\title{
Penerapan Kartu Stop Program Sebagai Faktor Penekan Kejadian Kecelakaan Kerja
}

\author{
Lintong Amalsyah Manurung ${ }^{1}$, Tatan Sukwika ${ }^{2, *}$ \\ 1,2Program Studi Magister Manajemen, Sekolah Pascasarjana, Universitas Sahid, Jakarta
}

\begin{abstract}
[Application of Stop Program Card as a Suppressive Factor for Occupational Accidents] The Stop Card program has been running for a long time, but in practice it has not been going well due to employee behavior less awareness. The purpose of this study was to determine and analyze the effect of K3 factors on the implementation of the stop program as an effort to reduce the occurrence of work accidents. The method used is the survey method. The sample amounted to 80 people. The analysis tool uses Smart-PLS. The results showed that (1) Internal and external factors have a significant effect on the implementation of the BBS stop program, external factors have a significant effect on the reduction of work accidents, the implementation of the BBS stop program has a significant effect on reducing work accidents, external factors have a significant effect on the implementation of the BBS stop program and reduce accidents. Work and (2) Internal Factors are not proven to reduce Work Accidents and Internal Factors are not proven to reduce Work Accidents through the Implementation of the BBS Stop Program. The recommendations are emphasized on improving the quality of the stop card observation card so that it continues to be tracked, and encourage workers to share with each other about the problems being observed.
\end{abstract}

Keywords: Internal external factors, Implementation of stop program BBS, Reduce work accidents

\begin{abstract}
ABSTRAK
Program Kartu Stop telah lama dijalankan, tetapi pada pelaksanaannya kurang berjalan baik akibat perilaku karyawan yang less awarness. Tujuan penelitian ini untuk mengetahui dan menganalisis pengaruh faktor K3 pada pelaksanaan stop program sebagai upaya mengurangi terjadinya kecelakaan kerja. Metode yang digunakan dengan metode survei. Sampel berjumlah 80 orang. Alat analisis menggunakan Smart-PLS. Hasil penelitian bahwa (1) Faktor Internal dan eksternal berpengaruh signifikan terhadap Pelaksanaan Stop Program BBS, Faktor Eksternal berpengaruh signifikan terhadap pengurangan kecelakaan kerja, Pelaksanaan Stop Program BBS berpengaruh signifikan terhadap Mengurangi Kecelakaan Kerja, Faktor Eksternal berpengaruh signifikan terhadap Pelaksanaan Stop Program BBS dan Mengurangi Kecelakaan Kerja dan (2) Faktor Internal tidak terbukti mengurangi Kecelakaan Kerja serta Faktor Internal tidak terbukti mengurangi Kecelakaan Kerja melalui Pelaksanaan Stop Program BBS. Rekomendasinya ditekankan pada peningkatan kualitas kartu pengamatan stop card agar terus di tracking, dan encourage pekerja supaya saling sharing tentang permasalahan yang di amati.
\end{abstract}

Kata kunci: Faktor internal eksternal, Pelaksanaan stop program BBS, Pengurangan kecelakaan kerja

*Alamat korespondensi

Alamat Afiliasi: Kampus Pascasarjana Usahid Jl. Jendral Sudirman No. 86, Jakarta 10220.

E-mail: tatan.swk@gmail.com
Histori Artikel:

Naskah masuk (received) : :27-04-2021

Naskah revisi (revised) : 17-05-2021

Naskah diterima (accepted) : :31-05-2021 


\section{PENDAHULUAN}

PT. X merupakan salah satu perusahaan yang bergerak di bidang minyak dan gas. Produk utama yang dihasilkan perusahaan ini adalah gas. Dalam peranannya sebagai produsen gas terbesar di Indonesia, PT. X juga menjalankan komitmennya dalam keselamatan dan kesehatan kerja. Salah satu program yang dilakukan di perusahaan ini untuk menciptakan budaya keselamatan di kalangan karyawan adalah dengan program STOP. Walau tingkat insiden di office hampir tidak ada, namun program ini dilakukan sebagai upaya preventif. Dengan program ini, karyawan dilatih untuk peka akan kondisi yang safe atau unsafe.

PT. X mengadopsi lisensi dari STOP program dari DuPont. Program STOP ini lazimnya digunakan di lapangan (site), karena bahaya dan risiko yang ada di lapangan tentunya lebih besar dari lingkup kantor. Namun untuk mengurangi risiko kejadian yang tidak aman, PT. X sudah mengaplikasikan program ini di kantor. Namun, pelaksanaannya kurang berjalan secara menyeluruh. Ini dikarenakan tidak semua divisi melakukan pemantauan dengan kartu STOP. Hal ini terjadi karena pengaruh dari perilaku karyawan yang less awarness terhadap keselamatan dan menganggap risiko keselamatan di kantor rendah. Perilaku ini yang menjadikan program STOP kurang efektif. Oleh karena itu, dilakukan suatu kajian untuk melihat gambaran perilaku karyawan terhadap implementasi Program Kartu BBS pada pekerjaan drilling dan workover, wellservice. Faktor-faktor yang identifikasi bahaya pada pekerjaan workover dan wellservice adalah (1) Kurang peduli dalam mengamati perilaku yang tidak aman dan kondisi yang tidak aman di sekitar area kerja dan (2) Kurangnya kesadaran dalam mengimplementasikan STOP Work authority (SWA).

Kasus kecelakaan kerja yang tercatat dalam perusahaan cukup tinggi. Selama 2020 tercatat 73 kasus dan 64 kasus kejadian yang mengakibatkan kerugian, melihat dari jumlah tahun 2014 total recordable 11 kejadian dan tahun 2015 meningkat menjadi 13 kejadian, hal ini mencerminkan adanya peningkatan jika dibandingkan antara 2014 dan 2015. Untuk karyawan yang tidak dapat kembali bekerja selama periode tertentu terlihat ada 1 karyawan ditahun 2014 dan tahun 2015. Hal ini menunjukkan bahwa data-data yang tercatat perlu untuk dilakukan kajian lebih lanjut untuk mencari penyebab sehingga dapat dilakukan pencegahan agar tidak terulang kembali.

Berdasarkan Tabel 1, kecelakaan sebagian disebabkan oleh terjadinya kesalahan manusia yang mengakibatkan terjadinya kecelakaan kerja terjadi Pada saat pengangkatan BOP dengan memakai chain hoist, rantai yang terjulur dirapikan dan kumpulkan di lantai lorong moonpool rig sebelum dimasukan ke dalam chain bucket. Posisi chain bucket terletak di lantai moonpool rig. Rantai berukuran $22 \mathrm{~mm}$ dengan panjang 25 meter. Proses pengangkatan BOP sudah berjalan tiga kali pergerakan dengan mengikuti prosedur yang ada. Pada pergerakan BOP ke empat, setelah IP merapikan rantai di lantai lorong moonpool rig terdapat bagian rantai yang keluar dari lantai lorong dan melorot ke bawah ke arah top deck STA Platform. Posisi IP berdiri di lorong moonpool tersebut sejajar dengan tumpukan rantai. Pada saat rantai melorot ke bawah ada sebagian rantai tersebut menggesek betis kaki kanannya. IP kemudian dibawa rekan kerjanya ke klinik. IP memakai APD lengkap, termasuk Safety Shoes (9 inch). Tidak ada pekerja yang berada di bawah BOP atau area Top Deck STA Platform saat insiden terjadi.

Melihat kondisi kecelakaan kerja diatas, perlu dikaji lebih dalam lagi agar kita dapat mengungkapkan secara detail faktor-faktor dan langkah penyebab dasar yang mendorong terjadinya kecelakaan atau kejadian yang merugikan. Untuk itu perlu diketahui faktor-faktor penyebab kecelakaan kerja dari kesalahan manusia, lingkungan organisasi serta lingkungan keselamatan kerja dan apa pengaruh terhadap perilaku tersebut. Data-data statistik tersebut diatas dengan menganalisis tingkat resiko dari masing-masing kejadian yang dapat merugikan, dikategorikan berpotensi menjadi tingkat resiko tinggi yang dapat mengakibatkan kerugian yang sangat signifikan terhadap berlangsungnya kegiatan-kegiatan sehari-hari. 
Tabel 1. Data Performance PT X tahun 2020

\begin{tabular}{|c|c|c|c|c|c|c|c|}
\hline \multirow[t]{2}{*}{ No } & \multirow[t]{2}{*}{ Kategori Insiden } & \multicolumn{6}{|c|}{ Tahun 2020} \\
\hline & & Juli & Ags & Sept & Oct & Nov-Dec & Total \\
\hline 1 & Fatality & 1 & - & - & - & - & 1 (April) \\
\hline 2 & LTI & - & - & - & - & - & 0 \\
\hline 3 & RWDC & - & - & - & - & - & 0 \\
\hline 4 & MTC & - & - & - & - & - & 0 \\
\hline 5 & FAC & 1 & - & - & - & - & 1 \\
\hline 6 & Nearmiss & - & - & - & - & - & 0 \\
\hline 7 & Property Damage & - & - & - & - & - & 2 \\
\hline 8 & Spill & 2 & - & - & - & - & 0 \\
\hline 9 & Manhours & 139,620 & 114,900 & 102,096 & 100,287 & - & 1037608 \\
\hline 10 & Safe Behavior & 10,488 & 576 & 7151 & 7088 & - & 77548 \\
\hline 11 & Unsafe Behavior & 231 & 176 & 211 & 188 & - & 2251 \\
\hline 12 & Unsafe Condition & 627 & 549 & 570 & 466 & - & 5582 \\
\hline
\end{tabular}

Sampai saat ini, relatif sedikit perhatian telah diberikan kepada keselamatan dalam literature perilaku organisasi, meskipun ada penelitian yang berkonsentrasi pada iklim keselamatan dan budaya keselamatan, belum adanya kajian-kajian dampak faktor-faktor organisasi seperti iklim keselamatan di organisasi, iklim kerja yang mengikuti keselamatan secara umumnya, dan prilaku individu yang pada dasarnya dengan meningkatkan pendidikan, pengetahuan, skill, serta motivasi kerja akan mengurangi dampak terhadap operasional organisasi. Tujuan penelitian ini adalah untuk mengetahui dan menganalisis pengaruh faktor internal dan faktor eksternal terhadap keselamatan dan kesehatan kerja dalam pelaksanaan stop program sebagai upaya mengurangi terjadinya kecelakaan kerja di PT. X.

\section{TINJAUAN LITERATUR}

Dalam undang-undang nomor 23 tahun 1992, pasal 23 tentang Kesehatan dan Keselamatan Kerja (K3) disebutkan bahwa Kesehatan dan Keselamatan Kerja (K3) diselenggarakan untuk mewujudkan produktivitas kerja secara optimal yang meliputi pelayanan kesehatan dan pencegahan penyakit akibat kerja (Waruwu \& Yuamita, 2016). Kecelakaan kerja merupakan hal tidak diinginkan dan tidak dapat di ketahui kapan terjadinya, tetapi semua itu bisa di antisipasi. Namun sekarang banyak perusahaan yang masih mengalami kecelakaan kerja. Hal ini karena masih kurangnya kesadaran dari sebagian besar masyarakat, perusahaan, pengusaha maupun tenaga kerja akan arti pentingnya K3 (Wirdati et al., 2015).

Mangkunegara (2014) berpendapat bahwa faktor-faktor kinerja terdiri dari faktor internal dan faktor eksternal (Sofyan, 2017): a) Faktor internal yaitu faktor yang dihubungkan dengan sifat-sifat seseorang; b) Faktor eksternal yaitu faktor-faktor yang mempengaruhi kinerja seseorang yang berasal dari lingkungan, seperti perilau, sikap, dan tindakan-tindakan rekan kerja, bawahan atau pimpinan, fasilitas kerja. dan iklim organisasi. Faktor-faktor internal dan eksternal ini merupakan jens-jenis atribusi yang mempengaruhi kinerja seseorang.

Perilaku Activator-Behavior Consequence ( $\mathrm{ABC}$ ) merupakan model perilaku yang biasanya digunakan dalam penerapan Risk Behavior Based Safety. Model perilaku ABC merupakan model analisis terapan yang dikemukakan oleh Skinner dan dipopulerkan oleh Krause guna untuk melakukakan perbaikan kinerja keselamatan yang berkelanjutan (Julaikah \& Tursilowati, 2020). Pencegahan cedera dan penyakit akibat kerja merupakan tindakan yg menguntungkan 
Orang/karyawan merupakan elemen terpenting untuk mencapai sukses dalam program. Namun, kondisi yang tidak aman tetap bermula dari perilaku yang tidak aman. Selain itu, program ini melatih tenaga kerja untuk mengamati, mencegah, dan melaporkan tindakan yang tidak aman, melatih pekerja mengamati dan menanamkan praktek kerja yang selamat. Dengan STOP dapat meningkatkan safety performance, mengurangi kemunduran produksi dan ram keselamatan dan kesehatan.

Hipotesis yang digunakan dalam penelitian ini yaitu: (a). Hipotesis satu atau $\left(\mathrm{H}_{1}\right)$ : Diduga faktor internal mempengaruhi keselamatan dan kesehatan kerja dalam pelaksanaan stop program sebagai upaya mengurangi terjadinya kecelakaan kerja di PT. X; (b) Hipotesis satu atau $\left(\mathrm{H}_{2}\right)$ : Diduga faktor eksternal mempengaruhi keselamatan dan kesehatan kerja dalam pelaksanaan stop program sebagai upaya mengurangi terjadinya kecelakaan kerja di PT. X.

\section{METODE}

\section{Populasi dan Sampel}

Populasi merupakan wilayah generalisasi yang terdiri atas objek atau subjek yang mempunyai kualitas dan karakteristik tertentu yang ditetapkan oleh peneliti untuk dipelajari dan kemudian ditarik kesimpulannya (Sugiyono, 2016). Berdasarkan pernyataan tersebut maka dapat diartikan populasi adalah keseluruhan subjek penelitian yang diselidiki dan hasilnya digeneralisasikan atau diterapkan kepada subjek tersebut. Adapun dalam penelitian ini populasinya adalah seluruh pekerja yang berjumlah 80 orang. Sugiyono (2016) menjelaskan bahwa teknik sampling jenuh adalah teknik penentuan sampel bila semua anggota populasi digunakan sebagai sampel. Maka dari itu, Penulis memilih sampel menggunakan teknik sampling jenuh karena jumlah populasi yang relatif kecil. Sehingga sampel yang digunakan pada penelitian ini berjumlah 80 orang yang disajikan pada Tabel 2 berikut :

Tabel 2. Jumlah Pekerja/Karyawan PT. X

\begin{tabular}{clc}
\hline No & \multicolumn{1}{c}{ Jabatan Pekerja } & Jumlah Populasi \\
\hline 1 & Drilling Crew & 36 \\
2 & Cathering Crew & 14 \\
3 & Service Company & 30 \\
\hline Total & $\mathbf{8 0}$ orang \\
\hline \multicolumn{2}{l}{ Sumber: Daily POB Updated Januari 2021 PT. $X$}
\end{tabular}

\section{Metode Pengumpulan dan Sumber Data}

Dalam pengumpulan data langkah-langkah yang diambil oleh penulis dalam memperoleh data berupa pengumpulan data primer dan data sekunder. Pengumpulan datak primer dilakukan dengan teknik penyebaran kuisioner kepada pekerja di PT. X. Adapun sumber data yang paling utama yaitu melalui kuesioner. Kuesioner disusun dalam bentuk pertanyaan-pertanyaan berdasarkan indikator penelitian. Dimana pertanyaan-pertanyaan dalam kuesioner tersebut diajukan dengan menyertakan format jawaban yang disusun berdasarkan Skala Likert. Skala Likert digunakan untuk mengukur sikap, pendapat dan persepsi seseorang atau sekelompok orang tentang fenomena sosial (Sugiyono, 2016).

Cara penilaian terhadap hasil jawaban dalam kuesioner dilakukan dengan menggunakan skala likert, dengan menghadapkan responden pada sebuah pernyataan yang nantinya akan diberikan bobot penilaian tertentu pada setiap pernyataan dengan skala Likert. Dalam hal ini peneliti memberikan pertanyaan tertulis kepada tenaga kerja di PT. X. Untuk memberikan nilai terhadap hasil jawaban dari kuesioner. Peneliti menggunakan skala likert dimana skala ini 
digunakan untuk mengukur sikap, pendapat, dan persepsi seseorang atau sekelompok orang tentang fenomenal sosial.

\section{Metode Analisis Data}

Dalam penelitian ini pengolahan data menggunakan program PLS dengan menggunakan metode partial least square yang dilakukan dengan tiga tahap yaitu: (1) Analisa Outer Model, (2) Analisa Inner Model, dan (3) Pengujian hipotesis.

\section{HASIL DAN PEMBAHASAN}

Evaluasi outer model dilakukan untuk menguji kelayakan measurement model yang digunakan baik dari sisi validitas dan reabilitas. Pada evaluasi outer model dengan indikator refleksif tingkat validitas dicari dengan pendekatan convergent validity dan discriminant validity sedangkan dari sisi reliabilitas dicari dengan pendekatan composite reliability. Convergent validity dari measurement model dengan indikator refleksif dapat diketahui melalui korelasi antara nilai indikator dengan konstruksnya dalam hal ini dapat dilihat dari hasil output outer loading. Output outer loading hasil estimasi dari PLS Algorithm dengan SmartPLS dapat dilihat pada gambar dan tabel berikut:

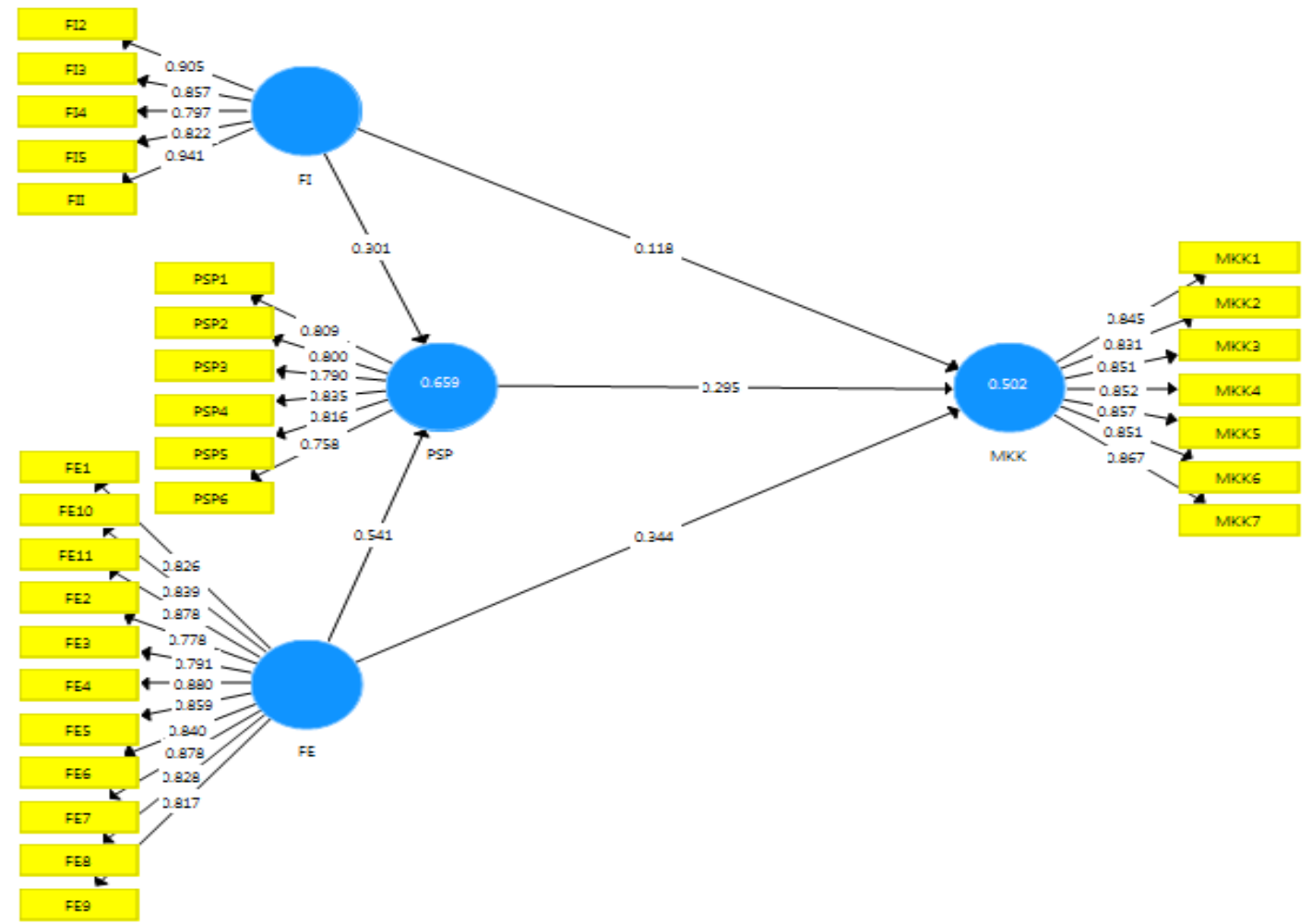

Gambar 1. Hasil Estimasi Model PLS (Algorithm)

Berdasarkan Tabel 3 dapat diketahui bahwa masing-masing outer loading FI_1 sampai dengan outer loading FI_5 pada variabel Faktor Internal mendapatkan nilai angka outer loading berkisar antara 0,797 - 0,941, variabel Faktor Eksternal mendapatkan nilai angka outer loading berkisar antara 0,778 - 0,880, variabel Pelaksanaan Stop Program BBS mendapatkan nilai angka outer loading berkisar antara 0,758 - 0,835, dan pada variabel Mengurangi Kecelakaan Kerja mendapatkan nilai angka outer loading berkisar antara 0,831-0,867, sehingga hasil output outer loading pada variabel penelitian ini di atas loading factor untuk seluruh indikator setiap variabel dapat dinyatakan memenuhi kriteria convergent validity, karena seluruh nilai loading factor masing- 
masing indikator lebih besar dari 0,50. Sehingga seluruh outer loading tersebut dapat dilakukan analisis statistik selanjutnya.

Adapun hasil outer loading variabel dalam penelitian ini dapat dijelaskan pada tabel 3.

Tabel 3. Hasil Outer Loading Variabel Faktor Internal, Faktor Eksternal

\begin{tabular}{ccccc}
\hline Pernyataan & $\begin{array}{c}\text { Faktor } \\
\text { Internal }\end{array}$ & $\begin{array}{c}\text { Faktor } \\
\text { Eksternal }\end{array}$ & $\begin{array}{c}\text { Pelaksanaan Stop } \\
\text { Program BBS }\end{array}$ & $\begin{array}{c}\text { Kecelakaan } \\
\text { Kerja }\end{array}$ \\
\hline 1 & 0,941 & 0,826 & 0,809 & 0,845 \\
2 & 0,905 & 0,778 & 0,800 & 0,831 \\
3 & 0,857 & 0,791 & 0,790 & 0,851 \\
4 & 0,797 & 0,880 & 0,835 & 0,852 \\
5 & 0,822 & 0,859 & 0,816 & 0,857 \\
6 & - & 0,840 & 0,758 & 0,851 \\
7 & - & 0,878 & & 0,867 \\
8 & - & 0,828 & & \\
9 & - & 0,817 & & \\
10 & - & 0,839 & & \\
11 & - & 0,878 & & \\
\hline
\end{tabular}

Keterangan: Valid dengan ketentuan masing-masing indikator $>0,5$

Sumber: Data diolah (2021)

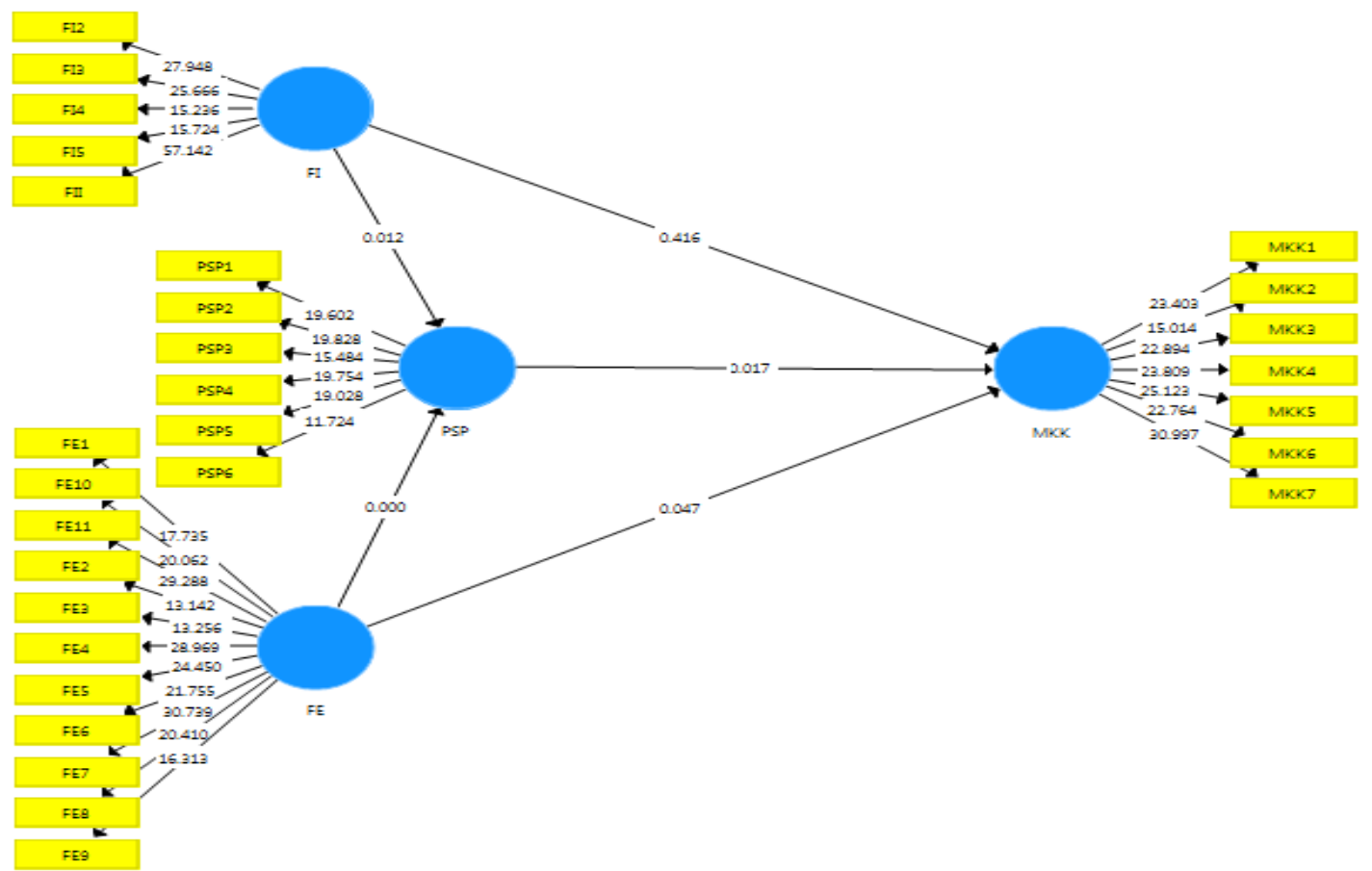

Gambar 2. Hasil Estimasi Model PLS (Bootsrapping)

Pengujian hipotesis menggunakan analisis full model Struktural Equation Modeling (SEM) dengan smartPLS. Dalam full model SEM dengan PLS selain memprediksi model, juga menjelaskan ada atau tidaknya hubungan (pengaruh) antar variabel penelitian.

Berdasarkan pada Tabel 3 diatas dapat dilihat pengaruh masing-masing variabel dengan melihat nilai koefisien jalur:

1. Pengujian Hipotesis Pertama $\left(\mathrm{H}_{1}\right)$. Hasil pengujian hipotesis pertama $\left(\mathrm{H}_{2}\right)$ bahwa Faktor Internal berpengaruh positif secara signifikan terhadap Pelaksanaan Stop Program BBS pada PT. X dapat DITERIMA. Artinya terbukti bahwa, semakin tinggi Faktor Internal yang dijalankan oleh perusahaan, maka semakin meningkat pula Pelaksanaan Stop Program BBS di PT. X. Faktor Internal berpengaruh positif secara signifikan terhadap Pelaksanaan Stop Program BBS adalah 
sebagai berikut: (a) Mencegah kecelakaan kerja dapat dilakukan dengan fokus mengurangi unsafe behavior seperti melakukan pengamatan kemudian di tuangkan ke formulir observasi perilaku selamat individu (OPSI) melaui system intranet PHKT, (b) Identifikasi unsafe act atau unsafe behavior dapat dilakukan dengan berbagai cara melalui mengobervasi bahaya ketika bekerja dengan menerapkan STOP Work authority atau Self stop work authority (SSWA), dan Hazard Hunt Program yang dilakukan setiap weekly periodic. Dimana crew drilling dilibatkan juga di dalam program ini. Hasil penelitian ini sejalan dengan penelitian terdahulu yang dilakukan oleh Endroyo (2010) bahwa pengetahuan (pengalaman) berpengaruh signifikan terhadap keselamatan dan kesehatan kerja dalam mengurangi kecelakaan kerja di Perusahaan Konstruksi Semarang.

2. Pengujian Hipotesis Kedua $\left(\mathrm{H}_{2}\right)$

Hasil pengujian hipotesis kedua $\left(\mathrm{H}_{2}\right)$ untuk perolehan original sample $(\mathrm{O})$ sebesar 0,541 dengan perolehan $p_{\text {value }}$ sebesar 0,000 , maka Faktor Eksternal berpengaruh positif secara signifikan terhadap Pelaksanaan Stop Program BBS pada PT. X. Artinya terbukti bahwa, semakin tinggi Faktor Eksternal yang dijalankan oleh perusahaan, maka semakin meningkat pula Pelaksanaan Stop Program BBS di PT. X. Faktor Eksternal berpengaruh positif secara signifikan terhadap Pelaksanaan Stop Program BBS sebagai berikut: (a) Tenaga kerja yang berperilaku aman dapat terhindar dari kecelakaan kerja perilaku seseorang selaras dengan lingkungan dan individu yang bersangkutan (b) Pekerja semakin terbiasa dengan mengimplementasikan budaya selamat di lingkungan kelurga ketika days off. Hasil penelitian ini sejalan dengan penelitian terdahulu yang dilakukan oleh Hartono dan Sugiyarto (2018), adanya peraturan produsedur K3 mampu meningkatkan pelaksanaan program pencegahan Keselamatan dan Kesehatan Kerja (K3) yang diterapkan pada Proyek Pembangunan Gedung di Tangerang dan Sekitarnya.

3. Pengujian Hipotesis Ketiga $\left(\mathrm{H}_{3}\right)$

Hasil pengujian hipotesis ketiga $\left(\mathrm{H}_{3}\right)$ untuk perolehan original sample $(\mathrm{O})$ sebesar 0,118 dengan perolehan $p_{\text {value }}$ sebesar 0,416 , maka hipotesis yang menyatakan bahwa Faktor Internal berpengaruh positif secara signifikan terhadap Mengurangi Kecelakaan Kerja pada PT. X dapat DITOLAK. Artinya tidak terbukti bahwa, semakin tinggi Faktor Internal yang dijalankan oleh perusahaan, maka semakin meningkat pula Mengurangi Kecelakaan Kerja di PT. X. Kesehatan dan keselamatan kerja merupakan salah satu faktor penting dalam kebijakan perusahaan mengenai program K3 yang harus diterapkan di perusahaan dan bukan hanya sekadar wacana. Kecelakaan kerja merupakan kecelakaan yang terjadi dalam lingkungan kerja yang dapat terjadi karena kondisi lingkungan kerja yang tidak aman ataupun karena kesalahan manusia. Faktor Internal tidak terbukti berpengaruh positif secara signifikan terhadap Mengurangi Kecelakaan Kerja sebagai berikut: (a) Faktor internal sangat penting untuk support pekerja di dalam mengurangi kecelakaan kerja karna faktor support supervisor yang selalu edukasi dan saling menguatkan untuk saling bekerja selamat (b) Follower internal yang tidak saling support dapat mempengaruhi factor kecelakaan kerja. Hasil penelitian ini sejalan dengan penelitian terdahulu yang dilakukan oleh Wirdati, Denny dan Kurniawan (2017) bahwa pengetahuan (faktor internal) tidak menyebabkan terjadinya kecelakaan kerja dalam menerapkan Work Permit di PT. X Semarang.

4. Pengujian Hipotesis Keempat $\left(\mathrm{H}_{4}\right)$

Hasil pengujian hipotesis keempat $\left(\mathrm{H}_{4}\right)$ untuk perolehan original sample $(\mathrm{O})$ sebesar 0,344 dengan perolehan $p_{\text {value }}$ sebesar 0,047 , maka hipotesis yang menyatakan bahwa Faktor Eksternal berpengaruh positif secara signifikan terhadap Mengurangi Kecelakaan Kerja pada PT. X dapat DITERIMA. Artinya terbukti bahwa, semakin tinggi Faktor eksternal yang dijalankan oleh perusahaan, maka semakin meningkat pula Mengurangi Kecelakaan Kerja di PT. X. Faktor Eksternal terbukti berpengaruh positif secara signifikan terhadap Mengurangi Kecelakaan Kerja sebagai berikut: (a) Faktor external secara significant dapat mengurangi kecelakaan kerja 
dimana faktor support dari keluarga adalah factor utama yang mendukung untuk kerja selamat, dimana pekerja adalah tulang punggung untuk keluarga (b) Faktor external yang lain adalah factor karier seseorang yang mengharuskan tidak ada traking kecelakaan kerja, dimana di tahun-tahun 2012 semasa harga minyak masih mahal rata-rata kontraktor drilling memberikan bonus tanpa kecelakaan kerja setiap tiga bulan sekali. Untuk noted bonus mostly pekerja semangat untuk mendapatkan bonus. Hasil penelitian ini sejalan dengan penelitian terdahulu yang dilakukan oleh Wijaya dan Paing (2018) bahwa faktor eksternal seperti peraturan K3 mudah di terapkan dengan konsisten, peraturan dan prosedur K3 sangat di perlukan mampu menjadikan tidak adanya kecelakaan kerja di lingkungan kerja Perusahaan Kontraktor di Surabaya.

5. Pengujian Hipotesis Kelima $\left(\mathrm{H}_{5}\right)$

Hasil pengujian hipotesis kelima $\left(\mathrm{H}_{5}\right)$ untuk perolehan original sample (O) sebesar 0,295 dengan perolehan $p_{\text {value }}$ sebesar 0,017 , maka hipotesis yang menyatakan bahwa Pelaksanaan Stop Program BBS berpengaruh positif secara signifikan terhadap Mengurangi Kecelakaan Kerja pada PT. X dapat DITERIMA. Artinya terbukti bahwa, semakin tinggi Pelaksanaan Stop Program BBS yang dijalankan oleh perusahaan, maka semakin meningkat pula Mengurangi Kecelakaan Kerja di PT. X. Hal ini dikarenakan masih tingginya angka kecelakaan dalam perusahaan serta adanya tuntutan global dalam perlindungan tenaga kerja diperlukan upayaupaya ke depan untuk mewujudkan tercapainya kecelakaan nihil pada kegiatan pelaksanaan program K3 di perusahaan, adanya kebijakan dari perusahaan mengenai pelaksanaan stop program BBS guna meningkatkan kesehatan dan keselamatan kerja para pekerja secara menyeluruh. Pelaksanaan Stop Program BBS berpengaruh positif secara signifikan terhadap Mengurangi Kecelakaan Kerja sebagai berikut: (a) Pekerja memahami bahwa semakin sering intervensi perilaku yang tidak selamat maka pekerja paham bahwa dapat mengurangi kecelakaan kerja (b) Setiap observasi yang bagus juga, manajemen PT X juga memberikan rewards setiap weekly safety meeting di rig Jack up AE-1. Hasil penelitian ini sejalan dengan penelitian terdahulu yang dilakukan oleh Wirdati, Denny dan Kurniawan (2017) bahwa kepatuhan dalam perusahaan berpengaruh signifikan terhadap kecelakaan kerja dalam menerapkan Work Permit di PT. X Semarang.

6. Pengujian Hipotesis Keenam $\left(\mathrm{H}_{6}\right)$

Hasil pengujian hipotesis keenam $\left(\mathrm{H}_{6}\right)$ untuk perolehan original sample $(\mathrm{O})$ sebesar 0,089 dengan perolehan $p_{\text {value }}$ sebesar 0,121 , maka hipotesis yang menyatakan bahwa Faktor Internal berpengaruh positif secara signifikan terhadap Pelaksanaan Stop Program BBS dan Mengurangi Kecelakaan Kerja pada PT. X dapat DITOLAK. Artinya tidak terbukti bahwa, semakin tinggi Faktor Internal yang dijalankan oleh perusahaan, maka semakin meningkat pula Pelaksanaan Stop Program BBS dan Mengurangi Kecelakaan Kerja di PT. X. Faktor Internal tidak terbukti berpengaruh terhadap Pelaksanaan Stop Program BBS dan tidak mampu Mengurangi Kecelakaan Kerja, hal ini tidak sejalan bahwa setiap program kecelakaan kerja semua terbukti mengurangi kecelakaan kerja dimana knowledge dan sharring stop program yang selalu di refresh akan mengingatkan pekerja minor, major setiap isi kartu pengamatan kartu unsafe act dan tindakan kondisi tidak aman, jadi stop program sangat berguna untuk mengurangi kecelakaan kerja baik di rig offshore maupun onshore. Hasil penelitian ini tidak sejalan dengan penelitian terdahulu yang dilakukan oleh Didukung pula oleh penelitian Latuconsin et al. (2019) bahwa pengetahuan (faktor internal) berpengaruh signifikan terhadap program K3 dan kecelakaan kerja pada karyawan PT. Maruki Internasional Indonesia Makassar.

7. Pengujian Hipotesis Ketujuh $\left(\mathrm{H}_{7}\right)$

Hasil pengujian hipotesis ketujuh $\left(\mathrm{H}_{7}\right)$ untuk perolehan original sample $(\mathrm{O})$ sebesar 0,160 dengan perolehan $p_{\text {value }}$ sebesar 0,027 , maka hipotesis yang menyatakan bahwa Faktor Eksternal berpengaruh positif secara signifikan terhadap Pelaksanaan Stop Program BBS dan 
Mengurangi Kecelakaan Kerja pada PT. X dapat DITERIMA. Artinya terbukti bahwa, semakin tinggi Faktor eksternal yang dijalankan oleh perusahaan, maka semakin meningkat pula Pelaksanaan Stop Program BBS dan mampu Mengurangi Kecelakaan Kerja di PT. X. Faktor Eksternal terbukti berpengaruh signifikan terhadap Pelaksanaan Stop Program BBS dan mampu Mengurangi Kecelakaan Kerja sebagai berikut: (a) Pekerja mempunyai spirit untuk selalu peduli satu sama lain untuk mengingatkan melalui penerapan patuh, intervensi satu sama lain (b) Pekerja selama bekerja selalu nyaman dengan penerapan SSWA/SWA dan sifat nya mengingatkan dan observasi tanpa ada dendam, atau tidak suka terhadap yang diamati melainkan yg mengobservasi peduli terhadap orang yang berperilaku yang tidak aman. Hasil penelitian ini sejalan dengan penelitian terdahulu yang dilakukan oleh Wirdati et al. (2017) bahwa sosialisasi K3 dalam perusahaan berpengaruh signifikan terhadap kecelakaan kerja dalam menerapkan Work Permit di PT. X Semarang. Didukung pula oleh penelitian lainnya Waruwu dan Yuamita (2016) komitmen, peraturan dan prosedur K3 (faktor eksternal) berpengaruh signifikan terhadap berkurangnya kecelakaan kerja pada Proyek Pembangunan Apartement Student Castle.

Tabel 3. Hasil Analisis Data

\begin{tabular}{|c|c|c|c|c|}
\hline Koefisien Jalur & $\begin{array}{l}\text { Original } \\
\text { Sample } \\
\text { (0) }\end{array}$ & $p$-values & Ketentuan & Keterangan \\
\hline \multicolumn{5}{|l|}{ Pengaruh Langsung (Path Coefficients) } \\
\hline $\begin{array}{l}\text { Pengaruh Faktor Internal terhadap } \\
\text { Pelaksanaan Stop Program BBS }\end{array}$ & 0,301 & 0,012 & $<0,05$ & Signifikan \\
\hline $\begin{array}{l}\text { Pengaruh Faktor Eksternal terhadap } \\
\text { Pelaksanaan Stop Program BBS }\end{array}$ & 0,541 & 0,000 & $<0,05$ & Signifikan \\
\hline $\begin{array}{lll}\text { Pengaruh Faktor Internal } & \text { terhadap } \\
\text { Mengurangi Kecelakaan Kerja } & \\
\end{array}$ & 0,118 & 0,416 & $>0,05$ & $\begin{array}{c}\text { Tidak } \\
\text { Signifikan }\end{array}$ \\
\hline $\begin{array}{l}\text { Pengaruh Faktor Eksternal terhadap } \\
\text { Mengurangi Kecelakaan Kerja }\end{array}$ & 0,344 & 0,047 & $<0,05$ & Signifikan \\
\hline $\begin{array}{l}\text { Pengaruh Pelaksanaan Stop Program } \\
\text { BBS terhadap Mengurangi Kecelakaan } \\
\text { Kerja }\end{array}$ & 0,295 & 0,017 & $<0,05$ & Signifikan \\
\hline \multicolumn{5}{|l|}{ Pengaruh Tidak Langsung (Indirect Effects) } \\
\hline $\begin{array}{lll}\text { Pengaruh Faktor Internal terhadap } \\
\text { Mengurangi Kecelakaan Kerja melalui } \\
\text { Pelaksanaan Stop Program BBS }\end{array}$ & 0,089 & 0,121 & $>0,05$ & $\begin{array}{l}\text { Tidak } \\
\text { Signifikan }\end{array}$ \\
\hline $\begin{array}{l}\text { Pengaruh Faktor Eksternal terhadap } \\
\text { Mengurangi Kecelakaan Kerja melalui } \\
\text { Pelaksanaan Stop Program BBS }\end{array}$ & 0,160 & 0,027 & $<0,05$ & Signifikan \\
\hline
\end{tabular}

Sumber: Data diolah (2021)

\section{KESIMPULAN}

Hasil penelitian dapat disimpulkan bahwa (1) Faktor Internal dan faktor eksternal berpengaruh signifikan terhadap Pelaksanaan Stop Program BBS, Faktor Eksternal berpengaruh signifikan terhadap Mengurangi Kecelakaan Kerja, Pelaksanaan Stop Program BBS berpengaruh signifikan terhadap Mengurangi Kecelakaan Kerja, Faktor Eksternal berpengaruh signifikan terhadap Pelaksanaan Stop Program BBS dan Mengurangi Kecelakaan Kerja dan (2) Faktor Internal tidak berpengaruh signifikan terhadap Mengurangi Kecelakaan Kerja serta Faktor Internal tidak berpengaruh signifikan terhadap Pelaksanaan Stop Program BBS dan Mengurangi Kecelakaan Kerja pada PT. X. PT. X diharapkan dapat meningkatkan kuaLitas kartu pengamatan stop card juga di tracking, dan encourage pekerja supaya saling sharring tentang apa yang di amati. 
Berdasarkan hasil penelitian ini, menunjukkan bahwa faktor internal tidak terbukti mampu mengurangi kecelakaan kerja, akan tetapi faktor internal mampu mempengaruhi adanya pelaksanaan stop program BBS, maka peneliti memberikan saran agar faktor internal (pengetahuan dan persepsi bahaya kelelahan) perlu ditingkatkan pemahamanya kepada para pekerja secara menyeluruh dan berkesinambungan. Peningkatan pengetahuan K3 dan persepsi bahaya kelelahan dilakukan dengan cara penanggung jawab perusahaan membekali ilmu K3 dan memberi bimbingan agar pengetahuan K3 dan persepsi bahaya kelelahan yang positif semakin bertambah guna meningkatkan keselamatan dan kesehatan kerja serta memberikan sosialisasi dan edukasi K3 sesuai dengan jadwal dan prosedur yang sudah ditentukan oleh perusahaan baik untuk keselamatan dan kesehatan kerja jangka pendek maupun jangka panjang.

\section{DAFTAR PUSTAKA}

Endroyo, B. (2010). Faktor-faktor yang berperan terhadap peningkatan sikap keselamatan dan kesehatan kerja (K3) para pelaku jasa konstruksi di semarang. Jurnal Teknik Sipil dan Perencanaan, 12(2), 111-120

Hartono, W., Purwandari, Y., \& Sugiyarto, S. (2018). Analisis sistem manajemen dan keselamatan kerja (SMK3) terhadap tingkat kecelakaan kerja pada proyek pembangunan gedung di Tangerang dan sekitarnya. Matriks Teknik Sipil, 4(1), 208-215

Julaikah, J., \& Tursilowati, S. Y. (2020). Behavior based safety sektor informal becak motor di Yogyakarta. Jurnal Kesehatan Kusuma Husada, 11(2), 193-204.

Latuconsin, N. A., Thamrin, Y., \& Fachrin, S. A. (2019). Faktor-faktor yang mempengaruhi kejadian kecelakaan kerja pada karyawan di PT. maruki internasional Indonesia Makassar. Jurnal IImiah Kesehatan Diagnosis, 14(1), 53-57.

Mangkunegara, A. (2014). Evaluasi kinerja sdm, cetakan ketujuh. Bandung: PT Refika Aditama.

Sofyan, A. (2016). Pengaruh kesehatan dan keselamatan kerja (K3) terhadap kinerja karyawan PT. bekaert Indonesia plant Karawang. Jurnal Manajemen \& Bisnis Kreatif, 2(1), 22-45

Sugiyono. (2016). Metode penelitian kuantitatif kualitataif dan kombinasi (mixed methods). Journal of Chemical Information and Modeling, 53(9), 240.

Waruwu, S., \& Yuamita, F. (2016). Analisis faktor kesehatan dan keselamatan kerja (K3) yang signifikan mempengaruhi kecelakaan kerja pada proyek pembangunan apartement student castle. Jurnal Rekayasa Spectrum Industri, 14(1), 65-78.

Wirdati, I. E., Denny, H. M., \& Kurniawan, B. (2017). Analisis faktor-faktor yang mempengaruhi kecelakaan kerja pada pekerja maintenance elektrikal dalam menerapkan work permit di PT. X Semarang. Jurnal Kesehatan Masyarakat, 3(3), 456-464.

Wijaya, R., \& Paing, J. (2018). Analisa faktor-faktor yang mempengaruhi keselamatan kerja karyawan perusahaan kontraktor di Surabaya. Jurnal Rekayasa Dan Manajemen Konstruksi, 6(2), 79-88. 